\title{
TREATMENT OF CANCER OF THE LIP BY RADIATION *
}

\author{
EVERETT S. LAIN, M.D. \\ Professor of Dermatology and Radiotherapy, Oklahoma \\ University School of Medicine \\ OKLAHOMA CITY
}

At the meeting of this Association in New Orleans, 1920, I presented a paper before this Section," "A Clinical Study of Epithelioma . of the Lower Lip," in which I considered more especially the pathologic anatomy and clinical classification of epithelioma of the lower lip, as observed and recorded in the private practice of my associate, Dr. M. M. Roland, and myself. In this paper, I mentioned only briefly the technic of treatment and results. Today, I am presenting to you briefly our technic of treatment by roentgen ray and radium of 248 consecutive cases of cancer of the lip which have occurred in our private practice from Jan. 1, 1909, to Dec. 31, 1921.

Tracing by letter of inquiry to family physician or patient, or by other methods, the present condition of each patient or the cause of death, and correlating the facts from such a number of patients with cancer of the lips who have been treated is no small undertaking, as those who have had experience will testify.

Also, I shall repeat these diagnoses have been made largely from a clinical rather than a biopsy examination. Judging from statistics from the Mayo Clinic, as given by Broders, ${ }^{2}$ and from the laboratories of Bloodgood, as quoted by Hazen, ${ }^{3}$ not less than 96 per cent. of our cases were of the prickle or of the squamous cell variety.

This total does not include a smaller number of cases in which the patients have been treated by interns or nurses in the Oklahoma State University, and in other hospitals of our city in which our services were only of a supervisory nature. This review of patients treated includes a goodly number who were treated several years prior to that enduring work toward arithmetical computation of roentgen-ray

* Read before the Section on Dermatology and Syphilology at the SeventyThird Annual Session of the American Medical Association, St. Louis, May, 1922.

1. Lain, E. S.: A Clinical Study of Epithelioma of the Lower Lip, J. A. M. A. 75:1052-1055 (Oct. 16) 1920.

2. Broders, A. C.: Basal Cell Epithelioma, 1912 Mayo Clinic Reprint, read before Southern Minnesota Medical Association, Mankato, Jan. 20, 1919.

3. Hazen, H. H.: Prickle Cell and Basal Cell Skin Cancers, J. A. M. A. 64: 958 (March 20) 1915. 
technic which was done by MacKee, ${ }^{4}$ Shearer and their co-workers. Also, much of our radium treatment covers a period antedating the more accurate methods of screening or filtering in order to get the effects of the more penetrating gamma rays.

Since about 1915, we have classified our patients into three groups, according to the location of the lesion upon the lip, and the degree of development, which to us also largely indicates the prognosis. This classification was presented in full in my former paper, and I shall repeat only briefly:

Group 1: Those lesions which are situated wholly on the cutaneous border of the lip, are not deeply indurated and are without palpable or other evidence of metastasis in adjacent glands.

Group 2: Those in which the lesion most commonly also overlaps the mucosa of the lip and are deeply indurated, and in which the adjacent submental or submaxillary glands are palpable. This group also includes a few cases of recurrences from former attempts at a cure by caustic applications or unsuccessful surgery.

Group 3: Those of obvious metastasis in more than immediately adjacent glands. Approximately, this entire group is composed of patients who have previously tried repeatedly some other methods of treatment and whose conditions are now hopeless so far as a final cure is concerned.

Medical literature on radiotherapy of cancer is becoming so voluminous and laboratory examination of radiated tissue has so frequently verified the following statements that they have become axioms to the experienced radiotherapist and are no longer debatable.

1. Immature and rapidly growing cells are more sensitive to radiations than those which have acquired their adult physiologic character. This is known as the law of Bergonie and Tribondeau. This change is more noticeable after radiations from the hard beta or the gamma rays of radium than after hard roentgen rays.

2. The most susceptible period in the life of this cell is the time of its division, when its nuclear life appears more amenable and accessable to this energy.

3. All types or characters of cells are not equally affected by the same degree or length of radiation, squamous or prickle cells and certain types of connective tissue cells requiring the greatest, basal lymphoidal and endothelic the least.

4. The lethal dose for a certain type of cell, such as the basal, may be only sufficient to stimulate to a more rapid growth a squamous or a connective tissue cell.

4. MacKee, G. M.: X-Ray and Radium in the Treatment of Diseases of the Skin, Philadelphia, Lea \& Febiger, 1921, p. 134. 
5. The shorter the waves of energy given off from radium or a roentgen-ray tube, the more penetrating and therefore the more effective are they in the disintegration of the cancer cell.

The more recent conjoined study of the physicist and radiotherapist has given to us a more accurate and scientific method of screening the rays so that roentgen rays and radium are now achieving cures in many cases of cancer formerly classified as inoperable or hopeless.

In the treatment of our cases, we have followed no invariable routine, except as regards certain proved or unquestioned procedures. One of the latter is the radiation of the submental and submaxillary glands by hard or gamma rays in all our cases of cancer of the lower lip.

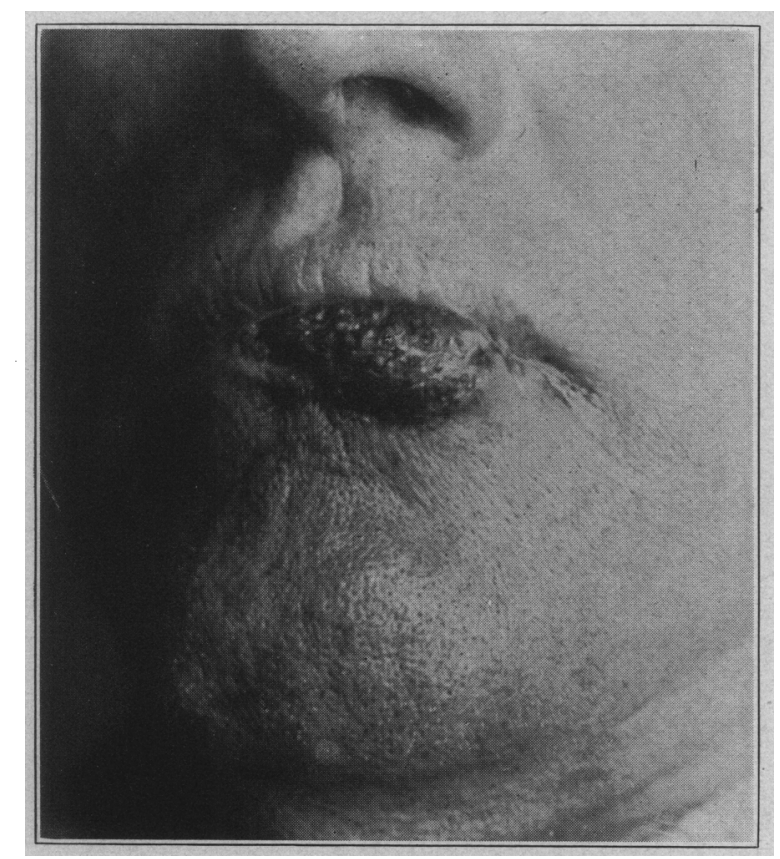

Fig. 1 (Class 1).-Cancer of lip.

The treatment of metastasizing areas has, in most cases, been given by roentgen ray, using $M$. A. of from 3 to 5, spark gap of from 6 to 10 inches $(15$ to $25 \mathrm{~cm}$.), anode distance of from 8 to 18 inches ( 20 to $45 \mathrm{~cm}$.) with filters from 1 to $4 \mathrm{~mm}$. of aluminum. Later, we added from 0.25 to $0.5 \mathrm{~mm}$. of copper, giving a time of twenty minutes to one hour each position. During the past two or three years, we have been giving a dosage to glands, expressed in modern terms, a K.V. 100 , M.A. 5, focal distance from 16 to 18 inches ( 40 to $45 \mathrm{~cm}$.), time from twenty-five to forty-five minutes, repeated as indicated in six weeks. 
This variation in technic does not appear so inconsistent when I explain that our evolution in treatment has consisted of an increasing potentiality over a period of fourteen years. Considering the cycle-like development of the pathologic cells, and reviewing our total treatments as well as the opinions and statistics of others, we are fully convinced that two or three properly timed and filtered doses of radium applied within intervals of a few days are more destructive to any type of cancer cell than the total given at a single exposure. The so-called fractional dosage, with either roentgen ray or radium, is much to be feared, although it is more successful if a nearly lethal instead of a stimulating dose for the pathologic cell has each time been given.

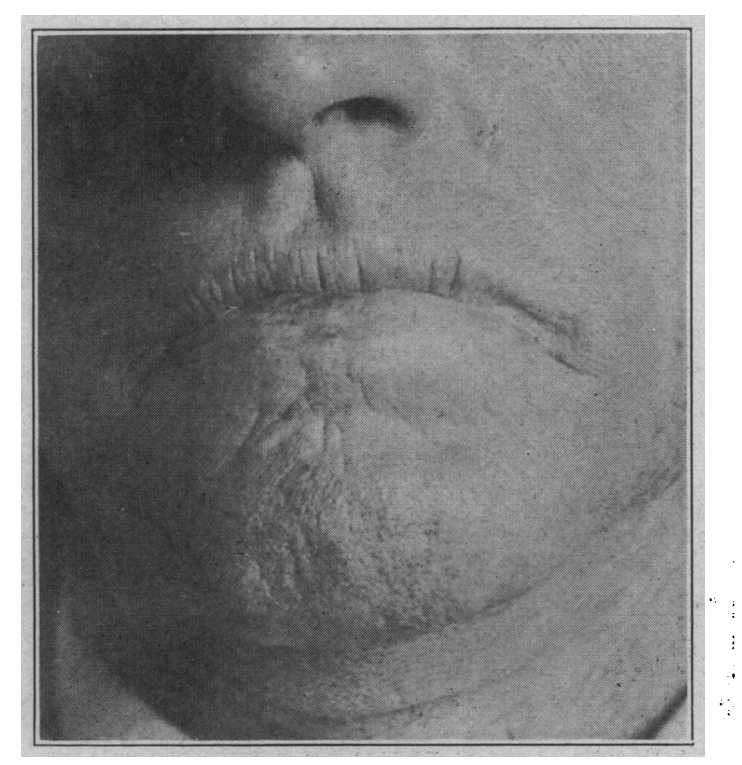

Fig. 2 (Class 1).-Patient shown in Figure 1, three years later.

Perhaps all radium specialists may not agree with our conclusions; still we have by experience been fully convinced that the destruction of a certain class of early and externally located basal cell cancers on the lips or elsewhere on the body may be more rapidly accomplished, and without an objectionable scar, by the use of the combined hard beta and gamma rays than by the gamma rays alone.

In a certain type of case under Group 1 , in which there is a proliferating keratotic elevation with only a mild degree of infiltration, it has been our custom, first, to apply a 10 or $20 \mathrm{mg}$. plaque, screened with $0.10 \mathrm{~mm}$. of aluminum for a period of two or three hours. This will cause, after ten or fifteen days, a reaction, which is followed, after twenty or thirty days, by degeneration and perhaps an exfoliation of all superficial pathologic cells. 
Before this reaction has begun or immediately after the first application, we apply a plaque of from 10 to $20 \mathrm{mg}$., with screening of 0.3 $\mathrm{nm}$. of brass, for eight to twelve hours. This filter permits only about 5 per cent. of the hardest beta rays and yet utilizes all the gamma rays for deeper effects. Thus we produce, in from four to six weeks, a perceptible softening and perhaps a complete disintegration of deeper cellular structures of cancerous nature.

In the treatment of Class 2, lesions of deeper and more extensive development, or of the squamous or the prickle cell variety, we first apply a 10 or $20 \mathrm{mg}$. plaque of radium over the lesion, screened with $0.3 \mathrm{~mm}$. of brass for from ten to fourteen hours, reinforced within a few days by a pack of from 100 to $160 \mathrm{mg}$. of radium screened with

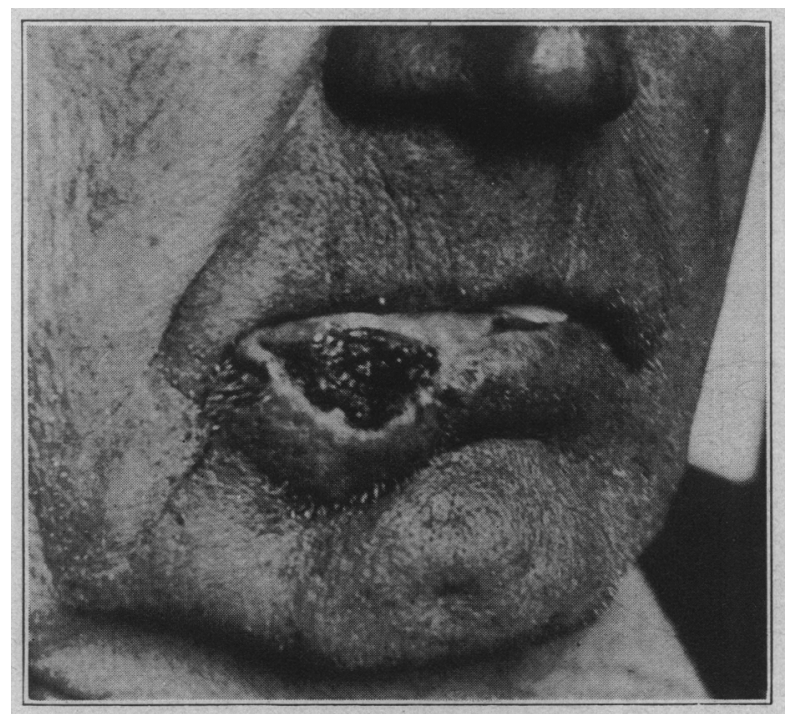

Fig. 3 (Class 2).-Cancer of lip, deeply infiltrated, involving submental glands.

$2 \mathrm{~mm}$. of brass and placed on a pad of gauze of from 1 to $3 \mathrm{~cm}$. in thickness. This pack is located over regions of possible metastasis for a total of from fifteen to twenty hours and this application may be repeated within a few days until a total of from 2,000 to $3,000 \mathrm{mg}$. hours have been given.

In a certain class of indurated or deeply nodular cancers of the lips, we follow the applications of the plaques with as many radium needles inserted from 1 to $4 \mathrm{~cm}$. apart as are necessary thoroughly to radiate the entire area of the cancerous growth. These are left for from three to five hours. Inserting the needles causes no severe pain if the entire growth is first injected with a 1 per cent. solution of procain. 
We are indebted to Drs. Boggs, Clark, Pfahler and others for calling our attention to this valuable advancement in the application of radium to this class of cancers.

In tabulating our total number of cases of cancer of the lips, I wish to call attention to the following interesting findings:

Twenty-seven patients were examined and, after having the method of treatment explained and prognosis given, refused treatment.

In eight cases, or about 3.2 per cent., the lesions were located on the upper lip. Two of these patients were females.

In nine of the total number of cases of cancer of the lip the patients were females, and five of these were users of tobacco. Of Class 3 , only three are now living and each still shows evidence of progressive cancer.

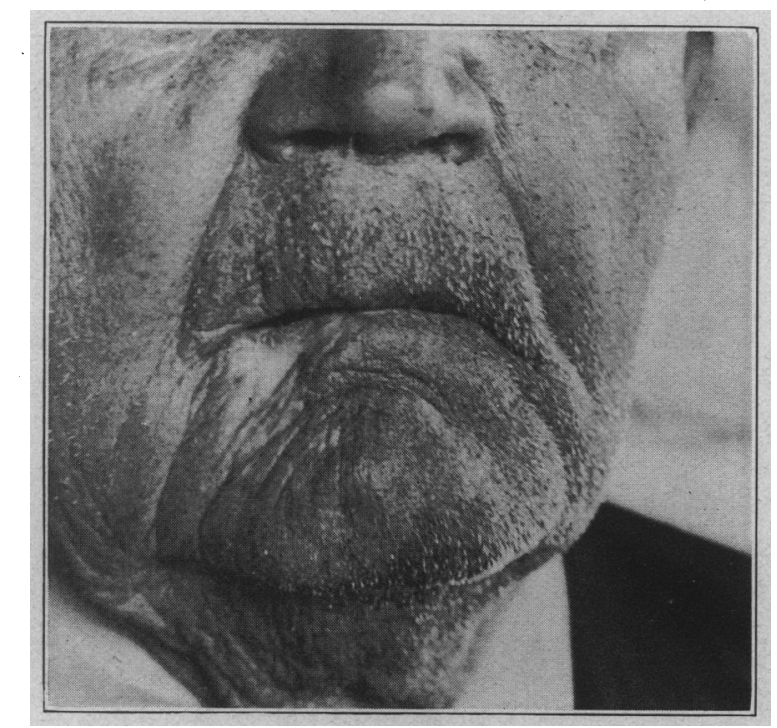

Fig. 4 (Class 2).-.Patient shown in Figure 3; no evidence of recurrence three years later.

Each of the eight cases of Class 3 and ten cases under Class 2 were recurrences following caustics or surgery. Of eight deaths under Class 2, five followed the employment of caustics and three were postoperative cases.

If we eliminate from Class 1 one patient who died from a cancer on the hand, one who died from a sarcoma at the point of the shoulder and one who died from generalized lymphosarcoma, conditions which could scarcely be classed as metastases from the lips, our percentage of cures in Class 1 is 98 plus.

Under Class 2, we note that, since the beginning of the more recent and much improved me:hods of radiation with a heavy kilo- 
voltage and radium packs, or, better still, when radium needles are inserted into the glandular metastasis, our percentage of cures promises to fall not far short of that of Class 1.

\section{CONCLUSIONS}

The cellular morphology of a cancer of the lip has less importance in the prognosis than the location or degree of development, or the age of the patient. We have repeatedly observed that, on account of a beginning atrophy of the lymph system, after a certain age the prognosis is better. Especially is this true in cancer of the lower lip.

Two Hundred and Forty-Eight Consecutive Cases of Cancer of the Lips

\begin{tabular}{|c|c|c|}
\hline Treatment and Results & Number & Percentage \\
\hline Refused treatment $\ldots \ldots \ldots \ldots \ldots \ldots \ldots$ & 27 & \\
\hline $\begin{array}{l}\text { Total taking one treatment only for palliative purposes } \\
\text { or taking up some other form of treatment......... }\end{array}$ & 13 & \\
\hline $\begin{array}{l}\text { Total number of cases of upper lip involvement: Class } 3, \\
\text { two patients, both now dead; Class } 2, \text { one living; } \\
\text { Class } 1, \text { six, all living................................ }\end{array}$ & 8 & \\
\hline Class 3 (all postoperative or postcaustic treatment), total & & \\
\hline $\begin{array}{l}\text { number of cases-each traced } \ldots \ldots \ldots \ldots \ldots \ldots \ldots \ldots \\
\text { Total number of patients living more than one year one: }\end{array}$ & 8 & \\
\hline $\begin{array}{l}\text { Total number of patients living more than one year, one; } \\
\text { two years, much improved, though not well.......... }\end{array}$ & 3 & \\
\hline Class 2: Total number of patients treated (seven cases & & \\
\hline 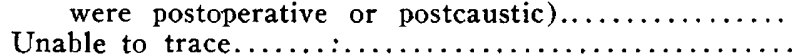 & 35 & \\
\hline 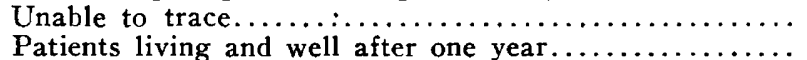 & 3 & \\
\hline $\begin{array}{l}\text { Patients living and well after one year } \ldots \ldots \ldots \ldots \ldots \ldots \\
\text { Well after three years, } 18 \text { patients treated } \ldots \ldots \ldots\end{array}$ & 32 & \\
\hline $\begin{array}{l}\text { Well after three years, } 18 \text { patients treated............. } \\
\text { Living and well more than five years, } 14 \text { treated; two died }\end{array}$ & 13 & 72.2 \\
\hline 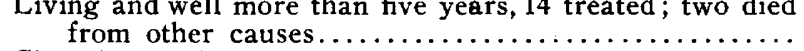 & 12 & \\
\hline $\begin{array}{l}\text { Class 1: Total number of patients treated to January, } 1922 \\
\text { Died of accident, two: committed suicide, one, each dur- }\end{array}$ & 156 & \\
\hline 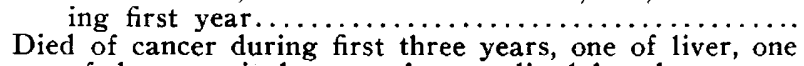 & 3 & \\
\hline 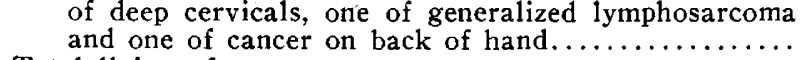 & 4 & \\
\hline Total living after one year $\ldots \ldots \ldots \ldots \ldots \ldots \ldots \ldots \ldots \ldots$ & 101 & \\
\hline Total number of patients treated more than three years. . & 89 & \\
\hline Total living, no recurrence. & 87 & 97.7 \\
\hline
\end{tabular}

We believe that a prickle or a squamous cell cancer, in the early stage of its growth, will undergo degenerative changes under radiations from either radium or roentgen ray just as the basal cell variety does. They differ only in the amount of radiation necessary and the technic of its application.

Finally, we believe that sufficient statistics verified both by clinical and by laboratory findings have now accumulated to justify the conclusion that cancer of the lip is equally and perhaps more amenable to treatment by roentgen ray or radium than by surgery, and in most cases radiotherapy is to be preferred. 


\section{ABSTRACT OF DISCUSSION}

ON PAPERS OF DRS. PARKHURST, HighMAN, TAUSSIG, PFAHLER AND LAIN

Dr. Gordon B. New, Rochester, Minn.: I do not believe any one is more enthusiastic about the use of radium in malignant disease of the head and neck than I am, but I believe that a great deal of harm has been done both to radium therapy and to patients when surgical conditions are treated with radium alone. I also believe that the good end-results of the treatment of epitheliomas of the lower lip with radium alone have been much overshadowed by the bad results. One must appreciate the fact that the diagnosis of these conditions must often be made microscopically. Fifty per cent. of questionable lesions of the lip are not malignant and must be excised for a microscopic diagnosis, so that the question of diagnosis must be considered in the cases of patients who are treated and cured with radium alone. If all lesions of the lower lip were excised for diagnosis, the mortality of epithelioma of the lip would be reduced a great deal: and I believe the cosmetic results in the cases I have seen treated surgically compare favorably with the results following radium. The glands of the neck should be removed in all cases of cancer of the lip. Radium should be given before and after operation, but not used alone in these conditions.

Dr. JoSEPH C. Bloodgood, Baltimore: The view I desire to emphasize is that at the present time the chief hope of preventing cancer is to get early cases, and I have demonstrated that 50 per cent. of the cases from which 1 have excised a $\mathrm{V}$-shaped piece from the lip are not cancer. Another thing we must bear in mind is this: some people with cancer, who, before the days of publicity, waited so that we never saw them until they had hopeless metastases, now come to the physician early. Publicity has done that. We must also know what condition we are treating. We cannot make progress if we do not. Fifty per cent. of my last 100 cases clinically called cancer were not cancer. We have reduced the cases of cancer from 85 to 70 per cent. by excluding conditions that are not cancer; you cannot exclude cancer by reading the pathologic report. I want the sections and want them studied and restudied. The medical schools of the country have not the money to give us to make these investigations.

Dr. F. J. Eichentaub, Washington, D. C.: Apparently dermatoses seen in the Middle West differ from those we see in Washington. I learn that ringworm of the scalp is cured by the application of a simple ointment, and now I learn that probably 98 per cent. of the cases of prickle cell cancer can be cured with radiotherapy. Our number of cases is small because we believe that prickle cell cancer of the lip is best treated with surgery, and so we send the patients to the surgeon. Of the fifteen patients we have treated, eight are dead or have recurrences; of the remaining seven, four have been well for only a year or two, so it is too early to call them cured. We have had one case treated just as a wart, then as a basal cell cancer, to the point of a third degree radiodermatitis. Before this reaction healed, the cancer recurred in the middle of the burn. When excised it proved to be a prickle cell cancer. This one case is enough to show that all prickle cell cancers cannot be destroyed by radiation, even when superficial and treated early. I cannot help but feel that surgery offers the best hope in prickle cell cancer of the lower lip. 
Dr. William H. Guy, Pittsburgh: There seems to be a complete agreement in regard to prevention of malignancy about the tongue and lip by propaganda and publicity, and certainly we are all indebted to Dr. Bloodgood, if to any one, for what he has done to encourage this work. Further, there can be no divergence of opinion regarding the necessity for removal of points of irritation, and, in general, the application of oral hygiene, thus preventing malignancy in early cases that are definitely benign. There is a wide divergence of opinion, however, as to what is to be done after it is eventually determined that we are dealing with malignancy. Dr. Bloodgood's results are excellent, but I am not convinced that they are better than those obtained by other methods. We cannot attack every case in the same way and obtain the best results. Each and every case must be treated according to its own individual requirements. It would appear that in the early type of case classified as "local, likely malignant," without gland involvement, that either with surgery, electrocoagulation, or radium practically 100 per cent. are cured. In cases with gland involvement we find an increasing discrepancy of opinion. We have been told that nothing but excision of the mass with wide excision of the glands in the area will do. The difficulties of such a procedure are seen when we review the gland drainage of the area. All metastatic glands are not palpable, as we know, and many palpable glands are not carcinomatous, but inflammatory. A combination of methods, surgery, electrocoagulation and radiotherapy may be required in such a case. If absolute diagnoses are necessary, I favor biopsy, and this should always be preceded by the application of a heavy dosage of roentgen rays or radium. If these elements devitalize pathologic cells, radiation preliminary to either radical removal or biopsy is definitely indicated. There is still room for an honest difference of opinion in these cases. I am convinced that by a combination of methods and especially by the hypodermic method of using radium in both the primary growth and palpable glands, followed by intensive raying of the entire gland-bearing area, results at least equivalent to those obtained by advance surgery may be attained.

Dr. Richard L. Sutton, Kansas City, Mo.: I was much interested in Dr. Bloodgood's suggestion regarding tobacco as a causative agent in cancer of the mouth. In the Middle West, sunburn probably plays a more important part than tobacco. We see many cases of lip involvement. Seborrheic keratosis of the keratoid type not infrequently is followed by the development of carcinoma, usually of the prickle cell type. The fact that primary lesions are much easier to cure than secondary ones was first pointed out, I believe, by the late Dr. Heidingsfeld of Cincinnati. In those cases in which carcinoma recurs in scar tissue, one gets into all sorts of trouble. This is especially true in those cases in which caustics (such as arsenic paste, and similar agents) have been used. A cancer quack can take a simple, uncomplicated case of basal cell cancer of the skin, a case that could be cleaned up in a short time with radium. or even with a curet and acid nitrate of mercury, and by the use of some "simple, farm remedy," convert it into a lesion which involves not only the underlying periosteum, but the bone as well; and the patient is promptly placed beyond the possibility of a permanent cure. Dr. Elmer Twyman of Kansas City has called attention to the fact that as a rule in carcinoma of the lip the lesion exhibits a tendency to travel laterally downward, instead of directly downward. In my work with him, we have found best a combination of methods, radium and cautery for the mouth and tongue lesions, with erythema doses of roentgen ray in the submaxillary and submental localities. Carcinoma of the lower lip so often develops from keratoses. Only an 
eagle-eyed genius can know when all of the keratosis has been included in the excised area, and if it has not been, recurrence is prompt, and extension rapid, along the line of the scar.

Dr. G. A. Wyeth, New York: Dr. Taussig said that he has prolonged life in cases of carcinoma of the tongue without mutilation, and he consoles himself with this although he says he has had only a fair number of recovered patients. I think if he had mutilated a little more at the start he would have prolonged more lives and prolonged life longer. As Dr. Taussig said, many men have reported excellent results with electrocoagulation in the treatment of carcinoma of the tongue. It is not hard to understand how these excellent results have been obtained. The use of heat in the tissues from within, or endothermy, as I like to call it, greatly reduces the danger of metastasis and the likelihood of recurrence. How? Before a malignant area is touched it is completely surrounded by a wall of coagulation necrosis which destroys or seals off the blood vessels and lymphatics to and from the part. A specimen for microscopic section can now be taken with impunity, after which the whole malignant area is coagulated in situ and then cut out with scissors as an inert, necrotic mass rather than as a group of viable cells. Endothermy comprises two different technics, as developed by Dr. Clark of Philadelphia-desiccation for lighter work, coagulation for heavier work-and through them the operator has a wide range of destruction at his command. This is my reason for thinking we have fewer recurrences than surgery unattended has.

Dr. C. H. BALl, Tulsa, Okla.: If 50 per cent. of cases are not cancer, why perform a mutilating operation? If the condition can be eradicated by radium or roentgen ray, why not try that first instead of mutilating the patient? In my experience with the roentgen ray, results have been the same as Dr. Lain's. The roentgen ray removes the cancer and effects a cure in 98 per cent. of the cases. Why, if you obtain 98 per cent. cures, should you resort to any other method? Traumatic interference breaks down the natural resistance of the body, and metastases occur much sooner.

DR. T. C. KENNEDY, Indianapolis: I cannot agree with Dr. Bloodgood about his cures by surgery. If that is true, we have poor surgeons in the West. During the last year I have had nine patients come to me for radiation who had been operated within a year or a year and a half. $\mathrm{He}$ is certainly doing better work than our surgeons in Indiana. I have had many cases of carcinoma of the lip in the last few years and our results have been uniformly good. I do not mean that we cure all cases, for no method will do that; but in the treatment of cancer of the lip our results are so successful that I believe every patient should be treated with radium before operation is resorted to. If you treat the patient for a few weeks and the condition does not yield, it is not too late for operation. I think in every case the roentgen ray should be used before operation is advised. I do not know whether I understood Dr. New correctly, but I think he said he preferred operation. The cosmetic results from radium are far superior to any surgical results, and if we can cure these patients in this way, why operate? If there are any cancer cells, we are far more likely to spread them by operating than we are to cure them. I am satisfied that in cancer of the lip radium is more successful than surgical treatment.

DR. F. W. CREGOR, Indianapolis: I think we have no right to call these cases cancer until they have been proved to be cancer. Fifty per cent. of Dr. Bloodgood's cases called clinically cancer were proved not to be cancer. I do 
not think we should attack his position. I can subscribe to the position of Dr. Guy and of Dr. New, and I can also visualize an injury to normal tissue cells about these growths as the result of intensive roentgen ray or radium therapy. It seems to me like sending an army of cripples out to perform the functions of able-bodied men. According to Kinlock, the roentgen-ray burns that do not heal within a year become carcinomatous because of the traumatism of the normal tissue cells by the roentgen ray; so that if we are attempting to destroy these cancer cells which possess a very high radiosensibility, we must realize that we are injuring tissue cells that possess a lesser degree of sensibility, even though we are not destroying the cancer cells as we hope to do.

Therefore, $I$ believe that the agent that destroys the macroscopically pathologic tissue, and the employment of radium, or especially roentgen rays, in the surrounding tissues afterward, in a dosage of not sufficient strength to impair normal tissue, but which we may hope will destroy pathologic tissue, is the method of choice.

Dr. John H. KIng, Nashville, Tenn.: Every case is a law unto itself, and we cannot use the same treatment in all. If we are treating a lesion on the lip, we should know the type of cancer and determine whether we are going to treat it with the roentgen ray, radium or electrocoagulation. If a case is treated by radium, the glands of the neck, submaxillary and submental, should receive deep roentgen-ray treatment or blunt dissection. I do not think we have a right to dismiss a patient without giving him the advantage of those two procedures. We know that many cases will recur, and we cannot say which they will be; if it is in our power to prevent these recurrences I think we should do so. Therefore, we should have a blunt dissection, a careful one, and a thorough radiologic treatment. A few weeks ago I had a case of recurrence in the submaxillary gland, that was quite large. I used the needle and heavy roentgen ray. The tumor-like formation disappeared remarkably quickly after three weeks. As the submaxillary and submental glands are the ones we first see affected, why can we not insert our radium needles in the areas we cannot strike with the rays? We cannot strike these glands because we cannot see them, but why cannot we do this as a prophylactic measure? It causes little discomfort, and we can leave them in for three, four or six hours as a prophylactic measure before any enlargement is observed.

Dr. Moses Scholtz, Los Angeles: One of the essayists has discussed roentgen-ray therapeutics in chronic nonmalignant inflammatory dermatoses, such as acne, lichens, psoriasis, eczemas, etc. There seem to be two points of view. The roentgen-ray experts and advocates of massive doses are looking for the largest dose that will not produce unpleasant after-effects. Another thing is to look for a minimum dose that will give the desired results. I think dermatologists should adopt the second point of view. There are essentially two dermatologic conditions calling for massive doses: malignancy and tinea of the scalp. In chronic inflammatory dermatoses we will get along much better with small fractional doses. I believe that in this group of dermatoses it is not only permissible, but distinctly helpful, to combine small fractional roentgen-ray treatments with exposures to ultraviolet light. By this means of additional sensitization we are able not only to reduce the number of roentgenray treatments to a minimum, but also the size of individual doses. I seldom use more than one-eighth or one-seventh of a skin unit with a spark gap of from 4 to 6 inches in chronic eczemas. lichens, acnes, etc. I cannot see the advisability of using one-fourth of a skin unit for many weeks in acne, a con- 
dition so benign and yielding so readily to therapeutics. Only very few, truly exceptional, cases would justify such heroic treatment. An overwhelming majority of acne cases will yield to ultraviolet light alternating with casual roentgen-ray treatments of much smaller aggregate dosage.

Dr. I. L. McGlasson, San Antonio, Texas: I take it from Dr. Bloodgood's and Dr. New's remarks that they meant the best type of surgery and perhaps compare it with ordinary radiotherapy. Then the results are not 100 per cent. perfect. All surgeons are not the best surgeons, nor are all radiotherapists the best in their line. All these things should be taken into consideration in discussing this subject in an effort to arrive at a conclusion. Dr. Bloodgood's statement is broad even for so eminent an authority. I am satisfied with my present treatment of cancer of the lip. I think I have overlooked something good in not following Dr. Pfahler's method of electrocoagulation, and I think that his plan is well worth while. Many patients with recurrence of cancer of the lip are sent to us by surgeons, and in these cases we get the worst results. If we have a failure, they say that radium is no good. I am curious to know whether the friends who talk against radium actually use it and have a sufficient amount. I think we should report our end-results, good or bad, until we can show something definite.

Dr. Davis W. Goldstein, Fort Smith, Ark.: I do not believe that in cases of cancer of the lip there can be any routine treatment. If we see a patient who has received no previous treatment, we believe that patient should receive radiotherapy. It does not make any difference whether you use radium, the roentgen ray or electrocoagulation to destroy the tumor. We formerly used carbon dioxid snow for the local lesion, with good results. Whatever method is used, the glands should be irradiated. If the patient has received previous treatment, I believe it is a surgical case. The cell is weakened by previous treatment, and it will not regenerate. I have had numbers of failures after the lesions were treated with caustics. The mucous membrane of the oral cavity is the most resistant of all tissues of the body to radium, and whether you use surgery, caustics or what-not, it is essential to take care of the lymphatics either by radium, roentgen-ray or complete block dissection.

Dr. Earl D. Crutchrield, Galveston, Texas: Some years ago I made a study similar to Dr. Parkhurst's. It seems to me that the reaction in these cases. is more a reaction of the cell to particular environment under which the attack occurs than a definite specific reaction to the basal cell or the prickle cell epithelioma. Drs. Highman and Rulison spoke of the stimulating roentgen-ray dosage. In an incomplete study during the last eighteen months $I$ have not been able to see any evidence of stimulation in any form of roentgen-ray dosage. I am not sure that the roentgen ray ever stimulates. The stimulation or reaction which may occur can be explained as a biologic reaction of the normal cells rather than as a stimulating reaction to the roentgen ray. In no case have I been able to see that mitoses were produced by the roentgen ray. One point in regard to surgery of the lip: Two or three years ago I studied serially sections of tumors of the lip which had been excised. Apparently on first examination many of these tumors seem to be small, localized lesions, but if serial sections are made, very often one is able to find small scattered cell nests in the edges of the lesions. The question then arises, When may we completely remove a lesion? If we knew that, then, perhaps, surgery would be the method of choice, for a great plastic surgeon; but if a piece of the lip is excised no man has the judgment to say whether or not the excision has 
been sufficiently extensive. We know that if ever a malignant growth is cut through, the possibility of metastases becomes very great. Therefore, since irradiation by the roentgen ray shows such a large percentage of cures radiation is certainly the method of cure; and electrocoagulation, which seals off everything, should be used as the method of removal.

Dr. Ben R. Kirkendall, Columbus, Ohio: I am glad that Dr. Pfahler has told us what to do for cancers of the lip that have been treated with roentgen rays but not cured. If we can cure these cases with electrocoagulation and not make them worse, it is a new method that can help us out. I think a great many nonmalignant growths of the lip would become cancers eventually. They are probably precancerous lesions, and the results we obtain with radium and the roentgen ray seem to be almost perfect in-these cases. Dr. Lain's paper, with its statistics, shows almost perfect results with radiation, so why perform a mutilating operation first. That should not be resorted to until it is necessary. I believe that these patients, whether treated by radiation or surgery, should all be irradiated under the jaw where glandular involvement may occur. I wish to caution about the application of radium after roentgen-ray treatment in cases of cancer of the lip. I have had several cases of cancer of the lip in which the patients have first been treated, I suppose, with massive doses of roentgen ray. When they came to me there was probably more radiation in the growth than could be determined. We have been told not to treat with radium or roentgen ray until from four to six weeks have elapsed since the previous treatment. I have waited as long as four months to apply radium following roentgen ray and have had the whole lip slough off in two cases. Dr. Pfahler's electrocoagulation might have taken care of these patients and prevented this mutilation.

Dr. H. J. Parkhurst, Toledo, Ohio: There is at least one difficulty attending the use of arsphenamin as a therapeutic test in differentiating between epithelioma and syphilis: the arsenical preparations often seem to accelerate the development of a malignant process when it is present. Therefore, great caution is necessary. Concerning the subject of the tissue reaction in malignant epitheliomas, the literature contains few references; and this work has been offered with the hope of stimulating investigation along this line.

Dr. R. H. Rulison, New York: Dr. Scholtz says he combines the roentgen ray with the ultraviolet light. I have had no experience with this. In general, perhaps, we are too conservative, but if we have an erythema, due, possibly, to a simple sunburn, we are likely to postpone treatment and wait for it to subside, and on that basis I think we would not care to combine the two methods. Dr. Crutchfield makes the criticism that in one place we speak of the stimulating effect of the roentgen ray. Whether there is such an effect, I do not know. I have no defense to offer for using it, except that there are certain authorities who think this may happen. It seems to me we are not accomplishing much in the discussion because of the difference in terms.

Dr. Laurence Taussig, San Francisco: As I have tried to point out, the diagnosis of carcinoma of the tongue is difficult to make in many instances. Dr. Parkhurst pointed out the possibility of stimulating the growth by arsphenamin but, having made up our minds as to the probable diagnosis, we must treat it with that diagnosis in mind, being ready to change our method of attack whenever indicated. I think the main thing in carcinoma of the tongue is to make a correct diagnosis as early as possible in order to institute proper treatment. 
Dr. George E. Pfahler, Philadelphia: We should treat each patient as an individual, and adopt the best treatment for each individual case. I have seen recurrences follow operations by the best surgeons in the country, whose names if mentioned would produce no doubt of their ability or good judgment. It must not be forgotten that the purchase of an amount of radium, either large or small, is no more a certainty of efficiency in its use than the purchase of a set of surgical instruments will guarantee a good operation. In my treatment with electrocoagulation, I always outline the surrounding edge in each case so that I know just how much is going to be taken away. That also seals off the lymphatics and blood vessels. I then trim it off with a pair of scissors, and at times the upper portion of that lession can be sent to the pathologist for examination. There is no bleeding, which proves that I have actually sealed off the blood vessels and lymphatics. I give radiation over the lip and chin and the submaxillary and submental areas. This should be added to any other form of treatment. When there are palpable lymphatic glands, I am not sure whether these had better be treated first by general radiation and then excised, or whether we had better treat with general radiation and then introduce radium needles into the lymph nodes. I think we must let time tell us which is best.

DR. E. S. LaIN, Oklahoma City: Dr. King has asked me what I think of the treatment with radium needles introduced into all metastasizing glands or where metastasis might occur. I think this is good procedure though not as a routine treatment. This was done in one of our cases. As regards the standardization of roentgen-ray and radium treatments, I do not think such treatment can be standardized. Surgical or medical treatments are not standardized for any disease. If we should reach such a period, progress in therapy will cease. One thing that Dr. McGlasson mentioned I have also found true. Namely, in my Group 3, the advanced cases, all patients had previously been treated by plasters or by incomplete surgery. The radiotherapist has too long been made a "dumping ground" for hopeless cases, as has been said. You recall that twenty-seven of my patients did not take treatment, and that was largely due to our resolve not to be made a dumping ground for all cases in which other forms of treatment had failed. As regards the claim of a cure in 98 per cent. of squamous or prickle cell malignancies, Dr. Pfahler misunderstood me. I said that Hazen, quoting from the Bloodgood laboratory, reported that most cancers of the lips were of the squamous or prickle cell variety. I said that we have been able to effect a cure in 97.7 per cent. in Class 1. In Class 2, in which the glands were freely palpable and in which we had other evidence of metastasis, we have a percentage of 72.2 per cent. of apparent cures after three years. Our methods have improved during recent years, though had we combined other methods, such as Dr. Pfahler's electrocoagulation method, other patients might have been cured. Let me repeat that $I$ do not believe we should entirely exclude surgery in the treatment of cancer of the lips. I do, however, insist that when we consider all phases of the patient's welfare and compare statistics on the various methods of treatment, we shall find in the use of radium and roentgen ray the most acceptable method. 